\title{
Rear surface passivation of ultra-thin CIGS solar cells using atomic layer deposited $\mathrm{HfO}_{x}$
}

\author{
Gizem Birant ${ }^{1,2,3, *}$, Jorge Mafalda ${ }^{3,4,5}$, Romain Scaffidi ${ }^{3,4,6}$, Jessica de Wild ${ }^{1,2,3}$, Dilara Gokcen Buldu ${ }^{1,2,3}$, \\ Thierry Kohl ${ }^{1,2,3}$, Guy Brammertz ${ }^{1,2,3}$, Marc Meuris ${ }^{1,2,3}$, Jef Poortmans ${ }^{1,3,4,7}$, and Bart Vermang ${ }^{1,2,3}$ \\ ${ }^{1}$ Institute for Material Research (IMO), Hasselt University (partner in Solliance), Wetenschapspark 1, Diepenbeek 3590, \\ Belgium \\ 2 IMEC division IMOMEC (partner in Solliance), Wetenschapspark 1, Diepenbeek 3590, Belgium \\ ${ }^{3}$ EnergyVille, Thorpark, Poort Genk 8310 \& 8320, Genk 3600, Belgium \\ 4 IMEC (partner in Solliance), Kapeldreef 75, Leuven 3001, Belgium \\ ${ }^{5}$ KTH-Royal Institute of Technology, Stockholm 11428, Sweden \\ ${ }^{6}$ Université Catholique de Louvain-UCLouvain, Louvain-la-Neuve 1348, Belgium \\ ${ }^{7}$ Department of Electrical Engineering, KU Leuven, Kasteelpark Arenberg 10, Heverlee 3001, Belgium
}

Received: 13 July 2020 / Received in final form: 8 October 2020 / Accepted: 18 November 2020

\begin{abstract}
In this work, hafnium oxide layer is investigated as rear surface passivation layer for ultra-thin $(550 \mathrm{~nm})$ CIGS solar cells. Point contact openings in the passivation layer are realized by spin-coating potassium fluoride prior to absorber layer growth. Contacts are formed during absorber layer growth and visualized with scanning electron microscopy (SEM). To assess the passivating qualities, $\mathrm{HfO}_{\mathrm{x}}$ was applied in a metal-insulatorsemiconductor (MIS) structure, and it demonstrates a low interface trap density in combination with a negative density of charges. Since we used ultra-thin devices that are ideal to probe improvements at the rear, solar cell results indicated improvements in all cell parameters by the addition of $2 \mathrm{~nm}$ thick $\mathrm{HfO}_{\mathrm{x}}$ passivation layer with contact openings.
\end{abstract}

Keywords: Solar cells / ultra-thin films / copper indium gallium selenide / surface passivation layer / hafnium oxide

\section{Introduction}

Today, CIGS based thin-film solar cells have achieved significant efficiency values, up to $23 \%$ [1]. With its tunable bandgap, being able to be transparent and flexible, it is widely preferred for thin-film applications. However, if the thickness of the absorber layer is chosen below $500 \mathrm{~nm}$, that is, ultra-thin, the conversion efficiency will decrease. The reason for this lower efficiency can be explained by the detrimental impact of increased back surface recombination and insufficient absorption due to decreased absorber layer thickness. Different approaches are being investigated to overcome these problems. At the back contact the application of a passivation layer, with or without optical structures to increase reflection, has provided the most promising results [2-6]. In this study, the proposed method is to use a dielectric layer as a rear surface passivation layer with contact openings realized by spin-coated alkali solution prior to CIGS layer growth. This method has

\footnotetext{
* e-mail: gizem.birant@imec.be
}

been proven to make contact openings in $\mathrm{AlO}_{\mathrm{x}}[4,5]$. In this contribution we use hafnium oxide $\left(\mathrm{HfO}_{\mathrm{x}}\right)$ as the dielectric layer, since it is proven to be a good passivation layer for c-Si and MOS structure by creating chemical and fieldeffect passivation, see [7-10]. $\mathrm{HfO}_{\mathrm{x}}$ is also tested before for CIGS solar cells as front and rear surface passivation layer, see $[11,12]$. In [12], it is concluded that $\mathrm{HfO}_{\mathrm{x}}$ has the potential to be an effective rear surface passivation layer with an appropriate contacting approach, like nanopatterning. In here we will apply a fast, cost-effective and simple approach, to create contact openings inside the hafnium oxide layer, and obtain an increase for all the solar cell parameters.

\section{Experimental section}

The proposed rear surface passivated solar cell structure is the following: $\mathrm{SLG} / \mathrm{Si}(\mathrm{O}, \mathrm{N}) / \mathrm{Mo} / \mathrm{HfO}_{\mathrm{x}} / \mathrm{KF} / \mathrm{CIGS} / \mathrm{NaF} /$ $\mathrm{CdS} / \mathrm{i}-\mathrm{ZnO} / \mathrm{ZnO}: \mathrm{Al} / \mathrm{Ni}-\mathrm{Ag}-\mathrm{Ni}$ Grids, as shown in Figure 1a. Solar cells have $550 \mathrm{~nm}$ thick, single-stage CIGS absorber layers with an active area of $0.5 \mathrm{~cm}^{2} .7 \mathrm{~nm} \mathrm{NaF}$ 


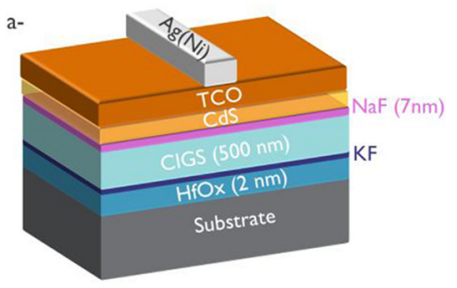

b-

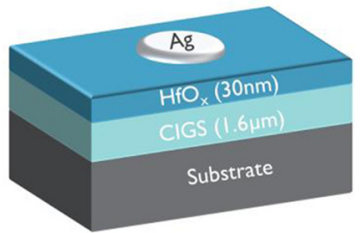

Fig. 1. Sample structure of (a) passivated solar cell and (b) MIS structure (Substrate: SLG/Si(O,N)/Mo).

3nm-thick $\mathrm{HfO}_{2}$ passivation layer

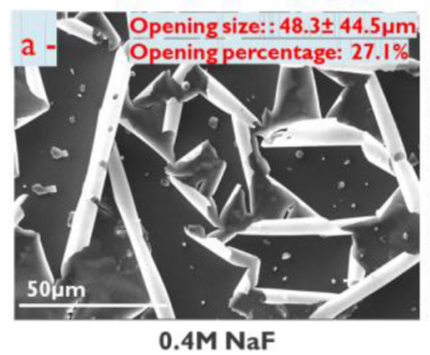

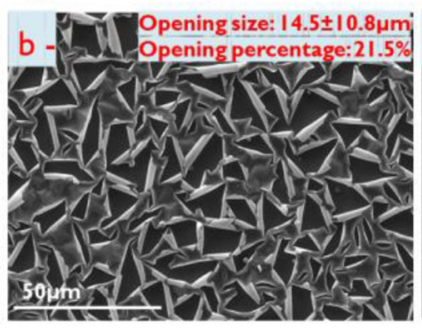

$0.4 \mathrm{M} \mathrm{KF}$

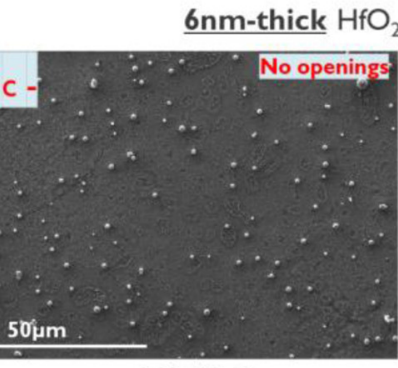

$0.4 \mathrm{M} \mathrm{NaF}$

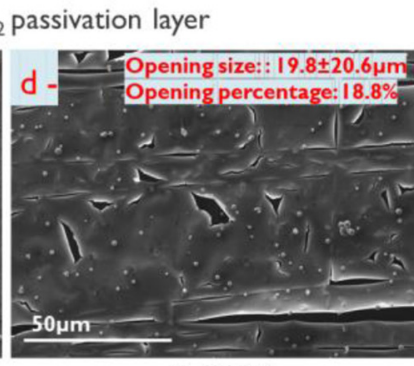

$0.4 \mathrm{M} \mathrm{KF}$

Fig. 2. SEM pictures of the test samples, (a) $3 \mathrm{~nm}$ thick $\mathrm{HfO}_{\mathrm{x}}$ and (c) $6 \mathrm{~nm}$ thick $\mathrm{HfO}_{\mathrm{x}}$ with $0.4 \mathrm{M} \mathrm{NaF}$, (b) $3 \mathrm{~nm}$ thick $\mathrm{HfO}$ and (d) $6 \mathrm{~nm}$ thick $\mathrm{HfO}_{\mathrm{x}}$ with $0.4 \mathrm{M} \mathrm{KF}$ solution. The opening sizes and areas were calculated via Gwyddion [9] (Magnification: 800×).

was added after absorber layer growth. No Ga-grading was used, and the $([\mathrm{Cu}] /([\mathrm{Ga}]+[\mathrm{In}])$, CGI ratio was approximately $85 \%$ and $([\mathrm{Ga}] /([\mathrm{Ga}]+[\mathrm{In}])$, GGI ratio was approximately $31 \%$, determined with XRF measurement. $2 \mathrm{~nm} \mathrm{HfO}_{\mathrm{x}}$ was deposited via $\mathrm{ALD}$ at $250^{\circ} \mathrm{C}$, and a growth rate of $0.14 \mathrm{~nm} /$ cycle with Tetrakis-EthylMethylAmino Hafnium (TEMAH) as the precursor and $\mathrm{H}_{2} \mathrm{O}$ as the reactant. KF was spin-coated on the $\mathrm{HfO}_{\mathrm{x}}$ layer. The reference sample has $0.4 \mathrm{M} \mathrm{KF}$, but no passivation layer. The MIS, on the other hand, has the following structure: $\mathrm{SLG} / \mathrm{Mo}(300 \mathrm{~nm}) / \mathrm{CIGS}(1.6 \mu \mathrm{m}) / / \mathrm{HfO}_{\mathrm{x}}(30 \mathrm{~nm}) / \mathrm{Ag}$ grids. Solar cells were characterized with current-voltage $(\mathrm{J}-\mathrm{V})$ and external quantum efficiency (EQE) measurements. From the dark J-V curves, the saturated current density $\left(\mathrm{J}_{0}\right)$ values were extracted. The MIS structure was characterized with capacitance-voltage (C-V) measurement. Contact openings were monitored via scanning electron microscopy (SEM).

\section{Results}

\subsection{Creation of the openings}

To study the creation of the openings inside the dielectric layer, we used a spin-coated alkali solution and then selenized the samples. The idea is to mimic the absorber layer deposition environment and to observe the effects of selenium environment on the combination of the di-electric and alkali solution. Since we know from our group's previous study, contact openings created spontaneously during the absorber layer deposition [4]. In line with our previous work on the $\mathrm{AlO}_{\mathrm{x}}$ passivation layer [4], our first intention was using $\mathrm{NaF}$ salt as our contacting approach. However, as can be seen from Figure 2, we cannot obtain good, that is, small and well-distributed openings in the 3 and $6 \mathrm{~nm} \mathrm{HfO}_{\mathrm{x}}$. For $\mathrm{KF}$ however, smaller and well distributed opening were observed, for both 3 and $6 \mathrm{~nm}$ thick $\mathrm{HfO}_{\mathrm{x}}$ layers. As a result, we decided to use the KF solution to create the contacts in the $\mathrm{HfO}_{\mathrm{x}}$ layer when applied as back contact passivation layer in solar cells, Figure 1a.

\subsection{Capacitance-Voltage (C-V) measurement}

In order to analyze the passivating properties of the $\mathrm{HfO}_{\mathrm{x}}$ dielectric layer, $\mathrm{C}-\mathrm{V}$ measurement was done on the MIS structure, with the aim to extract the interface trap density $\left(D_{i t}\right)$ and density of charges $\left(Q_{\text {eff }}\right)$. The sketch of the associated MIS structure is shared in Figure 1b.

Figure 3 a shows the $\mathrm{C}-\mathrm{V}$ curves at different frequencies. The $Q_{f}$ value was estimated from the following equation [8]:

$$
Q_{f}=\frac{c_{o x}\left(\varphi_{m s}-V_{f b}\right)}{e}
$$

where $\varphi_{m s}=4.5 \mathrm{eV}$, the estimated work function difference between silver $(\mathrm{Ag})$ and CIGS, the oxide capacitance per unit area, $c_{o x}=12 \mathrm{nF}$, and $e$ is the elementary charge in Coulombs. The flat band voltage, $V_{f b}$, is extracted as $0.5 \mathrm{~V}$ at $10 \mathrm{kHz}$, see Figure $3 \mathrm{~b}$. The $Q_{f}$ is then calculated to be $Q_{f}=-8.6 \times 10^{12} \mathrm{~cm}^{-2}$. This high concentration of negative $Q_{f}$ values reduce the net concentration of minority carriers at CIGS rear surface [9]. In other words, due to the Coulomb repulsion that creates a built-in electric field shielded the minority carriers to recombine at the rear surface, the negative $Q_{f}$ values indicate the field-effect passivation [10]. To assess the chemical passivation, $\mathrm{D}_{\text {it }}$ values were also determined [13]. The $\mathrm{D}_{\mathrm{it}}$ value is 

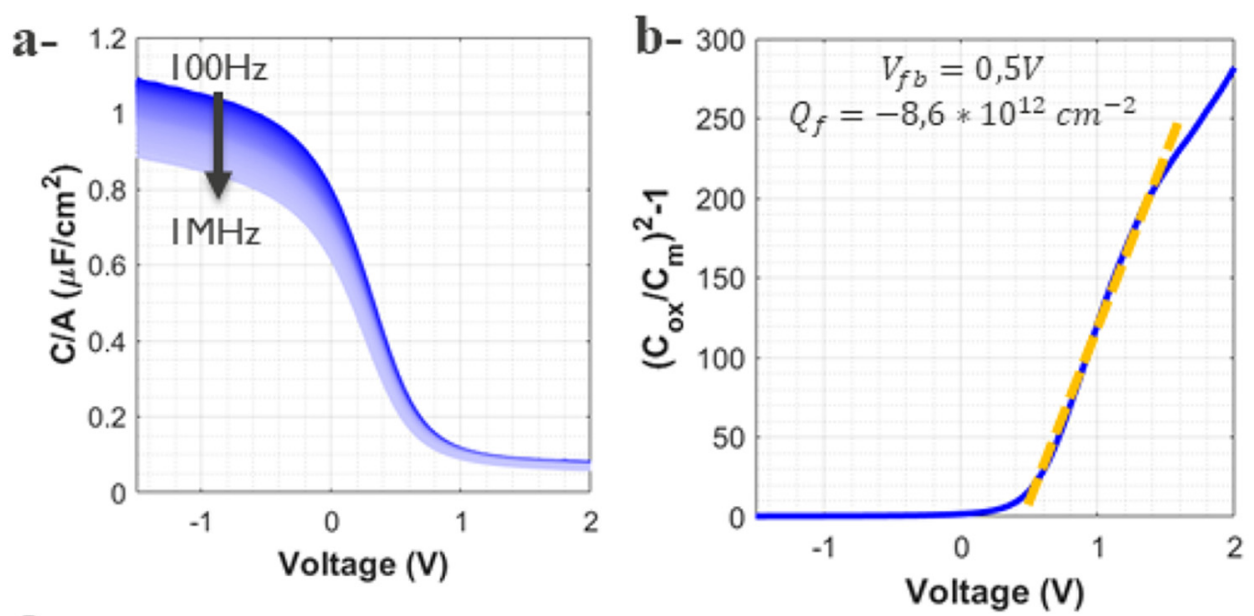

C-

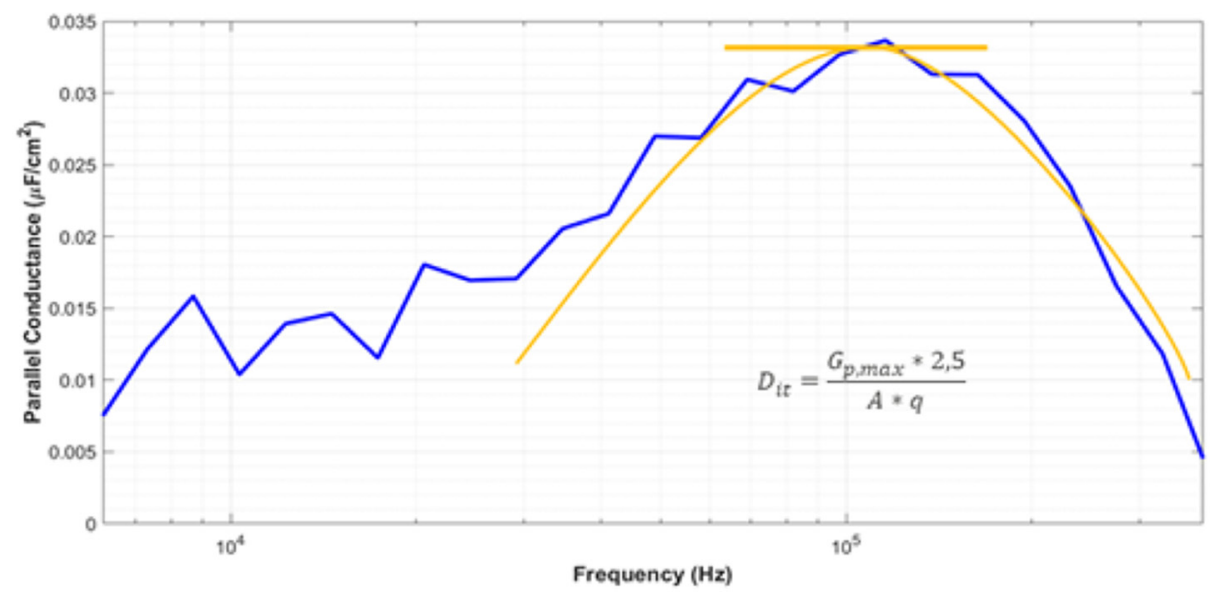

Fig. 3. (a) Capacitance-voltage $(\mathrm{C}-\mathrm{V})$ graph, (b) $\left(\mathrm{C}_{\mathrm{ox}} / \mathrm{C}_{\mathrm{m}}\right)^{2}-1$ as a function of voltage and (c) parallel conduction as a function of frequency.

respectively extracted with the Conductance method [14], and the High-Low Frequency Capacitance method [15], and it is estimated to be $6.1 \times 10^{11}$ and $4.8 \times 10^{11}$, Figure 3c. These two values of $D_{i t}$ fall in the expected order of magnitude for passivation properties of $\mathrm{HfO}_{\mathrm{x}}$ layers, and imply effective chemical passivation. According to the literature, annealed $\mathrm{HfO}_{\mathrm{x}}$ layers result in better $Q_{f}$ and $\mathrm{D}_{\text {it }}$ values $[16,17]$. The $\mathrm{HfO}_{\mathrm{x}}$ passivation layer was annealed naturally during absorber layer deposition at $540^{\circ} \mathrm{C}$, in this study. However, we could not perform $\mathrm{C}-\mathrm{V}$ measurement at degrees higher than $300^{\circ} \mathrm{C}$ for MIS structure due to experimental limitations. For $300^{\circ} \mathrm{C}$, $Q_{f}$, and $\mathrm{D}_{\text {it }}$ values and the polarity of the charges did not change.

\subsection{Solar cell results}

Solar cells were prepared with $2 \mathrm{~nm} \mathrm{HfO}_{\mathrm{x}}$ layer and various amount of KF solution were deposited, reference solar cell is also has KF prior to CIGS deposition. The electrical parameters of the devices were analyzed in this section. The arithmetic average of the six cells for each parameter, that is, Jsc, Voc, FF, $\mathrm{J}_{0}$, and $\eta$, for each combination is shown in Figure 4.
In this study, we used single-stage, un-graded, and ultra-thin CIGS absorber. Hence, the cell parameters for the reference sample are not on the same level as the record efficiencies that are shared in the introduction section (Fig. 4). However, deploying a passivation layer at the rear surface resulting in increased Voc values, which is the proof of the reduction in recombination. Decreased J0 values, on the other hand, correlate with Voc values and support this assumption.

The best Voc, that is, $595 \mathrm{mV}$, was achieved with a $2 \mathrm{~nm}$ thick $\mathrm{HfO}_{\mathrm{x}}$ layer in combination with $0.4 \mathrm{M} \mathrm{KF}$ (Fig. 4a). The associated $J_{0}$ value for this sample is the lowest value that we measured, which is $4 \times 10^{-9} \mathrm{~A} / \mathrm{cm}^{2}$ (Fig. 4b). However, this sample does not have the lowest average $\mathrm{J}_{0}$ values. The reason for that can be associated with the J-V curve of that sample (Fig. 4c). As can be seen from the J-V curve, there is a cross-over phenomenon that is mostly caused by high series resistance problems. For that sample, we believed that unoptimized contact openings lead to such high series resistance which ends up high $\mathrm{J}_{0}$ and low FF when we compared it to the $0.6 \mathrm{M} \mathrm{KF}$ sample. One of the most significant improvements is observed in the FF of the solar cells, especially with a sample that has a $2 \mathrm{~nm}$ thick $\mathrm{HfO}_{\mathrm{x}}$ layer with $0.6 \mathrm{M} \mathrm{KF}$. The reason for this improve- 

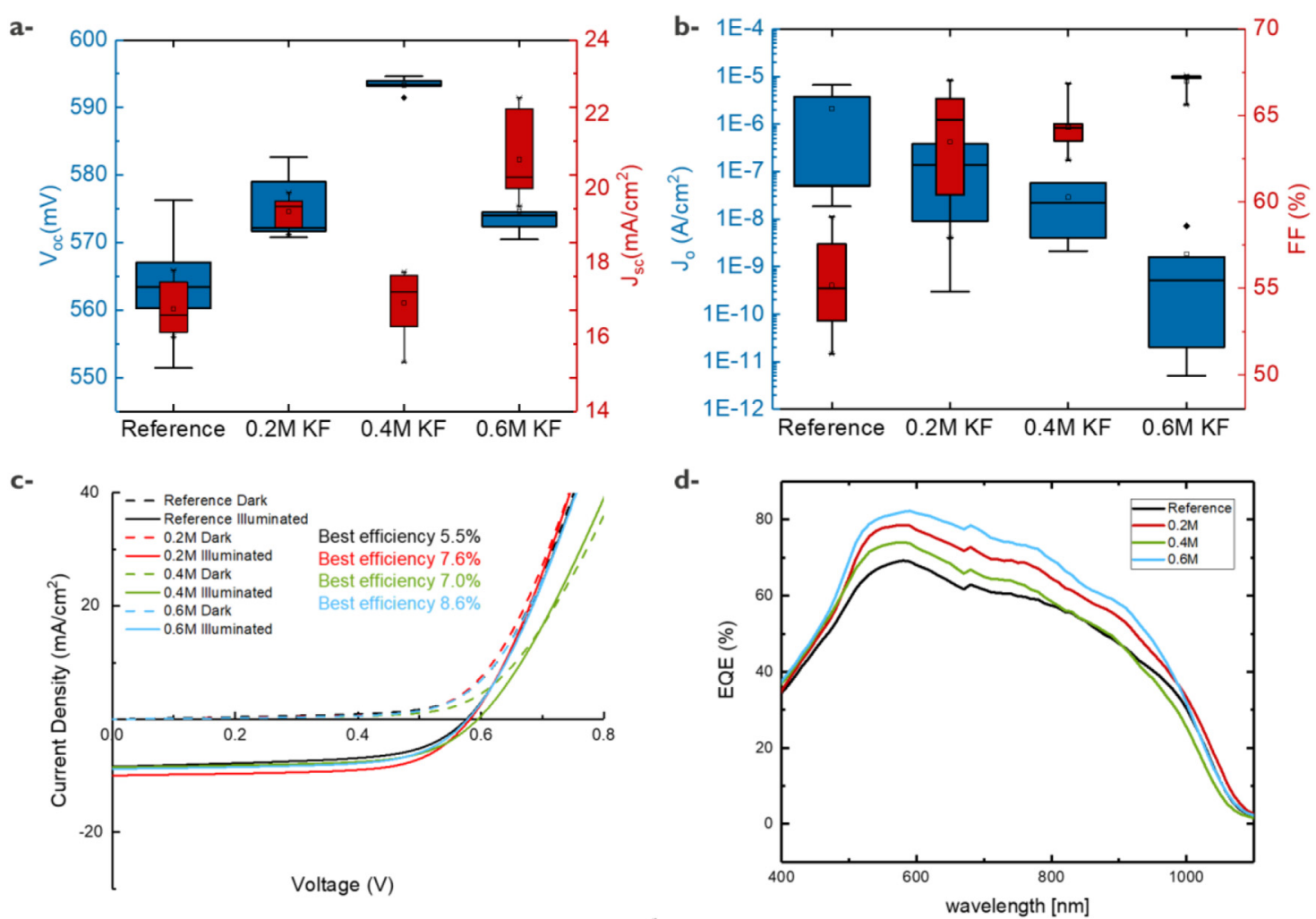

Fig. 4. J-V parameter comparison between reference (bare) and passivated ultrathin CIGS solar cells: (a) Voc (left axis) and Jsc (right axis), (b) $\mathrm{J}_{0}$ (left axis) and $\mathrm{FF}$ (right axis), (c) J-V curves with best efficiency values and (d) EQE responses for different KF molarity with $2 \mathrm{~nm}$ thick $\mathrm{HfO}_{\mathrm{x}}$ layer.

ment is due to the high shunt (Rsh) and the low series (Rs) resistance of this sample. Since the FF is inversely proportional to $\mathrm{Rsh}$ and proportional to $\mathrm{Rs}, \mathrm{FF}_{\mathrm{sh}}=\mathrm{FF}$ $\left(1-1 / \mathrm{R}_{\mathrm{sh}}\right)$, and $\mathrm{FF}_{\mathrm{s}}=\mathrm{FF}\left(1-\mathrm{R}_{\mathrm{s}}\right)$, this can explain the noticeable increase in FF [18]. When we investigate the relation between $\mathrm{FF}$ and $\mathrm{J} 0$ values, it can be seen that decreased $\mathrm{J}_{0}$ values result in increased $\mathrm{FF}$, as expected, see Figure 4b. The short circuit current density (Jsc) values are enhanced for all combinations (Fig. 4a). The increase in Jsc can be seen in the EQE responses of the samples. We observed better performances for all combinations in comparison to reference cell throughout most of the spectrum (Fig. 4d). As a result, increases in power conversion efficiencies were achieved for all combinations (Fig. 4c). For the solar cell with $2 \mathrm{~nm} \mathrm{HfO}_{\mathrm{x}}$ and $0.6 \mathrm{M} \mathrm{KF}$, there was an absolute $3 \%$ increase of the efficiency.

\section{Conclusion}

We have shown that $\mathrm{HfO}_{\mathrm{x}}$ has a potential to be used as a rear surface passivation layer for CIGS solar cells. With $2 \mathrm{~nm}$ thick $\mathrm{HfO}_{\mathrm{x}}$ layer in combination with a spin coated KF solution, we managed to create contact openings inside the dielectric layer during selenization. We gained $3 \%$ absolute increase in power conversion efficiency for the passivated solar cell, attributed to an increase in all cell parameters. With a MIS structure the quality of the layer were determined. The increased Voc and decreased
$\mathrm{J}_{0}$ values, in combination with the negative $Q f$ and low $D_{\text {it }}$ values prove that a rear surface passivation effect is created with $2 \mathrm{~nm}$ thick $\mathrm{HfO}_{\mathrm{x}}$ layer. As a result, we reached $595 \mathrm{mV}$ of Voc for ultra-thin $(550 \mathrm{~nm})$, single-stage CIGS solar cells. Furthermore, we believed that this study will be shed a light on using $\mathrm{HfO}_{\mathrm{x}}$ as the rear surface passivation layer for CIGS solar cells because it is still open for further optimizations. The contact openings and the thickness of the dielectric layer can be further optimized. Even, the tunneling effect should also be tested for layers thinner than $2 \mathrm{~nm}$.

This work received funding from the European Union's H2020 research and innovation program under grant agreement No 715027 .

\section{Author contribution statement}

All authors contributed equally to this work.

\section{References}

1. M.A. Green, E.D. Dunlop, J. Hohl-Ebinger, M. Yoshita, N. Kopidakis, A.W.Y. Ho-Baillie, Solar cell efficiency tables (Version 55), Prog. Photovoltaics Res. Appl. 28, 3 (2020)

2. G. Yin et al., Optoelectronic enhancement of ultrathin $\mathrm{CuIn}_{1-\mathrm{x}} \mathrm{Ga}_{\mathrm{x}} \mathrm{Se}_{2}$ solar cells by nanophotonic contacts, Adv. Opt. Mater. 5, 1600637 (2017) 
3. B. Vermang et al., Employing Si solar cell technology to increase efficiency of ultra-thin $\mathrm{Cu}(\mathrm{In}, \mathrm{Ga}) \mathrm{Se}_{2}$ solar cells, Prog. Photovoltaics Res. Appl. 22, 1023 (2014)

4. G. Birant et al., Innovative and industrially viable approach to fabricate $\mathrm{AlO}_{\mathrm{x}}$ rear passivated ultra-thin $\mathrm{Cu}(\mathrm{In}, \mathrm{Ga}) \mathrm{Se}_{2}$ (CIGS) solar cells, Sol. Energy 207, 1002 (2020)

5. D. Ledinek, O. Donzel-gargand, M. Sköld, J. Keller, M. Edo, Effect of different Na supply methods on thin $\mathrm{Cu}(\mathrm{In}, \mathrm{Ga}) \mathrm{Se}_{2}$ solar cells with $\mathrm{Al}_{2} \mathrm{O}_{3}$ rear passivation layers, Sol. Energy Mater. Sol. Cells 187, 160 (2018)

6. C.M. Iaru, Characterization of hafnium oxide thin films for applications in high efficiency c-Si solar cells, Eindhoven University of Technology, 2015

7. D. Necas, P. Klapetek, Gwyddion: an open-source software for SPM data analysis, Cent. Eur. J. Phys. 10, 181 (2012)

8. D.K. Schroder, Semiconductor material and device characterization, 3rd edn. (Wiley-Interscience, USA, 2006)

9. R. Kotipalli, B. Vermang, J. Joel, R. Rajkumar, M. Edoff, D. Flandre, Investigating the electronic properties of $\mathrm{Al}_{2} \mathrm{O}_{3} / \mathrm{Cu}$ (In,Ga)Se $\mathrm{Se}_{2}$ interface, AIP Adv. 5, 107101 (2015)

10. R.R. Kotipalli, Surface passivation effects of aluminum oxide on ultra-thin CIGS solar cells, Université Catholique de Louvain, 2016
11. J. Löckinger et al., The use of $\mathrm{HfO}_{2}$ in a point contact concept for front interface passivation of $\mathrm{Cu}(\mathrm{In}, \mathrm{Ga}) \mathrm{Se}_{2}$ solar cells, Sol. Energy Mater. Sol. Cells 195, 209 (2019)

12. D. Ledinek, J. Keller, C. Hägglund, W.C. Chen, M. Edoff, Effect of $\mathrm{NaF}$ precursor on alumina and hafnia rear contact passivation layers in ultra-thin $\mathrm{Cu}(\mathrm{In}, \mathrm{Ga}) \mathrm{Se}_{2}$ solar cells, Thin Solid Films 683, 156 (2019)

13. W. Shockley, W.T. Read, Statistics of the recombinations of holes and electrons, Phys. Rev. 87, 835 (1952)

14. E.H. Nicollian, J.R. Brews, Extraction of interface trap properties from the conductance, in: MOS (Metal Oxide Semiconductor) Physics and Technology (Wiley, 2003), pp. 212-221

15. S.M. Sze, K.K. Ng, Metal-insulator-semiconductor capacitors, in: Physics of Semiconductor Devices (Wiley, 2006), p. 219

16. X.Y. Zhang et al., Surface passivation of silicon using $\mathrm{HfO}_{2}$ thin films deposited by remote plasma atomic layer deposition system, Nanoscale Res. Lett. 12, 324 (2017)

17. X.Y. Zhang et al., Simulation and fabrication of $\mathrm{HfO}_{2}$ thin films passivating si from a numerical computer and remote plasma ALD, Appl. Sci. 7, 1 (2017)

18. A.B. Meinel, M.P. Meinel, P.E. Glaser, Applied Solar Energy: An Introduction, Phys. Today 30, 66 (1977)

Cite this article as: Gizem Birant, Jorge Mafalda, Romain Scaffidi, Jessica de Wild, Dilara Gokcen Buldu, Thierry Kohl, Guy Brammertz, Marc Meuris, Jef Poortmans, Bart Vermang, Rear surface passivation of ultra-thin CIGS solar cells using atomic layer deposited $\mathrm{HfO}_{\mathrm{x}}$, EPJ Photovoltaics 11, 10 (2020) 